\title{
Strategic collaborative quality management and employee job satisfaction
}

\author{
Ali Mohammad Mosadeghrad*
}

\section{Abstract}

Background: This study aimed to examine Strategic Collaborative Quality Management (SCQM) impact on employee job satisfaction.

Methods: The study presents a case study over six years following the implementation of the SCQM programme in a public hospital. A validated questionnaire was used to measure employees' job satisfaction. The impact of the intervention was measured by comparing the pre-intervention and post-intervention measures in the hospital. Results: The hospital reported a significant improvement in some dimensions of job satisfaction like management and supervision, organisational policies, task requirement, and working conditions.

Conclusion: This paper provides detailed information on how a quality management model implementation affects employees. A well developed, well introduced and institutionalised quality management model can improve employees' job satisfaction. However, the success of quality management needs top management commitment and stability.

Keywords: Strategic Collaborative Quality Management, Employee Job Satisfaction, Hospital

Copyright: ๑ 2014 by Kerman University of Medical Sciences

Citation: Mosadeghrad AM. Strategic collaborative quality management and employee job satisfaction. Int J Health Policy Manag 2014; 2: 167-174. doi: 10.15171/ijhpm.2014.38
Article History:

Received: 2 December 2013

Accepted: 23 April 2014

ePublished: 27 April 2014

\section{Introduction}

Quality management has been widely used in manufacturing and service industries to enhance employee motivation (1), improve quality of products and services (2), increase customer satisfaction (3), reduce rework and waste (4), increase profit and market share (5), and enhance business competitiveness (6-8). Quality management emphasizes customer focus, teamwork, continuous quality improvement, and systematic process management. Unlike the traditional quality assurance approaches, the concept of change in quality management is continuous and participatory, involving all employees in the process of quality improvement of their own activities.

There are various strategies for applying quality management in an organisation to improve products and services quality. These include Total Quality Management (TQM), Strategic Quality Management (SQM) (9), Strategic Total Quality Management (STQM) (10), Global Quality Management (GQM) (11), and Strategic Collaborative Quality Management (SCQM) (12). Furthermore, standards-based approaches (e.g. ISO 9000 standard) and quality award models (e.g. Deming Quality Award, European Foundation for Quality Management Model, and Malcolm Baldrige National Quality award) were accepted as guides to quality management implementation. While quality management has been suggested in theory to be effective for improving performance, its application in healthcare sector involves many difficulties (13-15). The limited success of quality management in healthcare organisations led the author to search for a more viable solution, and as a result, the SCQM model was created $(12,16)$. SCQM provides a system of quality management with thirteen constructs, of which eight are enablers and five are results. It provides a framework to strive for excellence by continuously improving overall organisational performance (employee results, customer results, supplier results, society results, and organisation results) through leadership and management, strategic quality planning, corporate quality culture, total continuous learning, employees management, customer management, resource and partnership management, and process management (16).

The SCQM model is an integrated quality management system, a combination of strategic management, quality management, and project management. It integrates continuous quality improvement into all three steps of strategic management (i.e. strategy formulation, strategy implementation, and strategy evaluation). Organisations formulate strategic quality goals and objectives, develop action plans, allocate resources, implement the action plans and evaluate the progress towards achieving strategic quality goals. The project management approach enhances the effectiveness and efficiency of action plans through planning, implementing, monitoring and controlling purposeful, welldefined and timely quality improvement projects. A project management approach helps to build a culture of quality and learning throughout the organisation (12).

SCQM involves changes in the structure, context (culture, values, and political system) and processes of an organisation. Such a change provides lasting and significant positive results. Systems thinking, process mapping, and process capability analysis in the SCQM model help identify opportunities to improve outcomes by improving structures and processes. Further, the SCQM's approach to the change is fundamental, gradual, and evolutionary. It considers a comprehensive change at individual, teams, and organisational levels. The focus of SCQM is both internal and external customers' requirements. 
Employees (Internal customers) are encouraged to identify and meet external customers' needs and expectations. In SCQM, the emphasis is on redesigning simpler, standardised, and more effective processes; determining reasonable and achievable objectives for processes; and improving them continually and continuously until objectives are achieved. Employees using problem-solving techniques evaluate the ability of the processes to reduce variation and provide high quality and defect-free services. They plan for the desired situation and change the organisation accordingly. As a result, they would be more motivated and committed (17).

Successful quality management implementation can increase employees' quality of work life (18), job satisfaction $(19,20)$, organisational commitment (21), and decrease employee absenteeism (22) and turnover (23). However, some scholars argue that quality management creates high-pressure working environments, increases job demands, and negatively affects employees' well being (24-26). Thus, the impact of quality management on employee job satisfaction remains a research question and the empirical evidence is mixed and debatable. Successful SCQM implementation requires employees' support. The SCQM initiative needs employee's knowledge, skills, abilities, passion, motivation, persistence, responsibility, accountability, and a quality-oriented attitude. Therefore, the SCQM programme aims to develop and manage the capabilities of employees, promote fairness and equality, involve, encourage; and enable employees to contribute to the achievement of the organisational goals and recognise their achievements. The SCQM practices such as visionary leadership, education, training, strategic quality planning, effective communication, employee empowerment, teamwork, reward, and recognition theoretically contribute positively to employees' satisfaction. On the other hand, SCQM practices such as customer management, supplier management, process management and evaluation, and control may increase job burden and result in employees' job dissatisfaction.

It is important to analyse how SCQM implementation affects employees. Therefore, this study aims to describe the consequences of SCQM implementation in the employees' working conditions, workload, job security, task requirements, and fringe benefits. Hence, this study attempts to investigate the following hypothesis: "The SCQM implementation has a positive effect on employees' job satisfaction".

\section{Methods}

\section{Purpose and objectives}

The SCQM model was implemented in a public hospital using participatory action research. This study aimed to examine the effects of the SCQM intervention on employees' job satisfaction in this hospital.

\section{Design}

A case study design was employed using a longitudinal method of data collection to assess the impact of SCQM implementation on employees' job satisfaction in a public hospital over a period of 6 years (between 2005 and 2011). The data collection was a time-series design with one measure as a baseline and three after the intervention. The objective of the pre- mid- and post- action data collection was to ascertain the impact of SCQM implementation on employees' job satisfaction. Figure 1 illustrates the points in time the measurements were carried out.

\section{Setting}

The study was conducted in a medium size public general hospital (Hospital 'A'), that implemented the SCQM model. The hospital had 517 employees in January 2006.

\section{Data collection and analysis}

A questionnaire was used to measure employees' job satisfaction (27). The questionnaire contained nine dimensions: salaries and benefits, recognition and promotion, management and supervision, co-workers, task requirement, organisation policies, working conditions, nature of the job, and job security. This questionnaire had 36 items (4 items in each domain). A further four items were also included in the questionnaire: employees' overall job satisfaction, ability to do their job well, intention to leave the organisation if they received a good offer from other healthcare organisations, and the hospital recommendation to others for work. The questionnaire utilizes a Likert-type scale with six response alternatives ranging from 'Strongly disagree' (weighted 1) to 'Strongly agree' (weighted 6) for each of the 40 items. The scores were then standardised to a percentage scale.

The sampling method was stratified random sampling. The first set of data was collected before the introduction of the SCQM model in the experimental hospital (December 2005) to be used as a benchmark. The second, third, and fourth sets of data were collected in September 2007, September 2008, and September 2011. There were no obvious differences in the demographic characteristics of samples between the four time intervals.

The difference between the four data sets was measured to find out the impact of SCQM implementation on hospital performance. All data were analysed using SPSS 11 (SPSS Inc., Chicago, IL, USA).

\section{Results}

Hospital 'A' began to implement the SCQM programme in early 2006. The ambition of the Top Management Team (TMT) was to increase hospital efficiency and reduce the

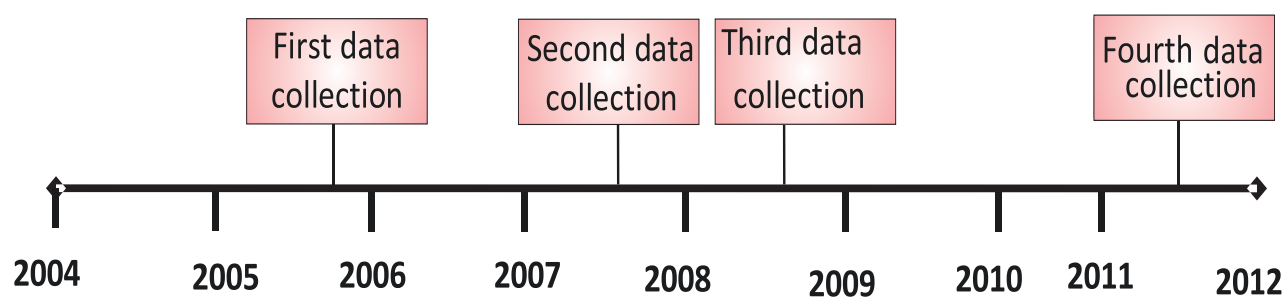

Figure 1. The time of data collection 
increasing trend of costs. As a result, most of front-line managers were replaced and radical changes were applied. Radical changes and downsizing led to changes in the personal work situation and generated resistance among employees. The top management team realised that personnel expenses comprised a large proportion of hospital expenses. Therefore, they used time and motion studies to optimize the number of staff for each department. In addition, employees' fringe benefits decreased. The hospital was in debt to suppliers and TMT thought applying these policies could help pay part of the debt to the suppliers. Due to these policies, employees were mostly dissatisfied with the management.

Although TMT acknowledged the need for change, their actions were not in favour of employees. Lack of trust between TMT and employees, and consequently employees' apathy towards change were the main reasons for the failure of organisational change at the hospital. Furthermore, TMT lacked experience in initiating and managing the change. As a result, employees' participation in the change process was low. Based on problems encountered in the hospital, there were some corrective actions taken to resolve the problems. Firstly, the hospital president was changed in early 2006. The new president, a psychiatrist, had enough managerial experience. The new hospital president appointed an experienced person as the hospital manager. Subsequently, the most respected and experienced staff were appointed as middle and front-line managers. They all had enough managerial experience. As a result, the fear of job security was overcome. In the next move, the new TMT clarified the link between quality and hospital productivity for employees.

A user-friendly SCQM guidebook was prepared to assist in setting up the SCQM system and guide the change process. The manual contains a general overview of SCQM's theoretical foundation (i.e. basic principles, benefits, and core elements), training curriculum and implementation method.

The introduction of SCQM in the hospital was fundamental, gradual and evolutionary. An infrastructure for the SCQM programme was established comprising of (i) a quality management council, (ii) a quality management department, (iii) a quality steering committee, (iv) functional and crossfunctional quality teams, and (v) a quality audit team. The quality management council created a 5-year strategic quality plan and defined quality goals. The strategic quality plan contained specific quality goals and objectives for each of the five dimensions of performance: employee, customer, supplier, organisation, and society. An annual operational plan was prepared, describing actions that would help the hospital meet its operational goals.

TMT supported a learning environment where employees were encouraged to share their ideas and information to enhance their knowledge and skills. Training was designed and delivered in three stages. In the first stage, senior and middle managers were trained in quality management concepts, skills, and techniques. In stage two, managers attended managerial and leadership skills training courses. The courses included leadership, planning, motivation, HRM, change management, participative management, teamwork, continuous improvement, customer relationship management, and controlling. In the third stage, sufficient quality awareness training was delivered to employees. This training was focused on developing quality-related knowledge and skills, teamwork and effective communication skills. The objective of the training programme was not only to explain the concept of SCQM principles and practices, but also to raise morale and soften resistance to change. Education and training were deemed to be the biggest facilitator in SCQM implementation. The hospital began gradually and cautiously the implementation of the SCQM programme by structural, cultural, and procedural changes. The physical structure was changed to suit the needs of both internal and external customers in order to improve processes. The mechanistic structure of the hospital was changed by initiating functional and crossfunctional teams, increasing employee responsibility and authority, and decreasing vertical coordination and control. In addition, personnel policies dealing with performance appraisal and rewards were changed.

As part of structural changes, angiography, endoscopy, peritoneal dialysis, spirometry, ICU for poisoned patients, and echocardiography wards or units were added to the hospital. Furthermore, Accident and Emergency (A\&E) department, internal medicine wards, CCU, dialysis, the operation theatre, radiology, colonoscopy, sonography, ICU, central sterilisation, the main kitchen, restaurant, stores, the switch board room, and cash office were renovated and equipped with new equipment. These changes were expected to result in an increased numbers of patients.

In order to develop a participative culture, a Suggestion Scheme was launched in early 2006. Employees contributed to improvement by actively participating in the Suggestions Scheme. Management has seriously considered those suggestions and recommendations. The hospital attempted to initiate Total Productive Management (TPM) practice in mid 2006. Therefore, an equipment engineering office was established and staffed with three motivated and competent personnel to improve the overall utilisation of equipment. The TPM programme improved effective equipment management as well as the technical skills and morale of hospital employees. A positive attitude, ownership, and concern were developed among employees. As a result, equipment defects and breakdown rates, and consequently repairing costs were reduced. The hospital has been using the $5 \mathrm{~S}$ system as part of a "Total Productive Maintenance" system in order to develop a culture of order, safety, and responsibility.

The next phase of the SCQM programme-the procedural changes-commenced formally in September 2007. Functional and cross-functional teams were formed to identify and solve quality problems. A quality steering committee was created to support functional and cross-functional teams. Extensive education and training were provided to develop employees' capabilities on a continuous basis. Employees were encouraged to use the ten-step quality improvement method to optimise their working processes. They were encouraged to identify, flowchart, optimise, and stabilise the processes. They were further asked to define objectives for the processes, determine key performance indicators and achievable targets for each process, measure processes, identify the gap between the expected and the actual performance, identify the problems, find the roots of the problems, build solutions, develop a plan, execute solutions and evaluate the effectiveness of the improvements. Involving the teams in all stages of the action 
research motivated them to plan and implement changes for a better quality of care. The ten-step quality improvement method was found very useful for learning and improvement. The hospital CEO resigned in April 2010. Although the new hospital president was interested in improving the quality of healthcare services, he was not actively involved in quality management activities. He was mainly involved in his professional clinical duties. He did not pursue longterm overall organisational success. He was instead focused on meeting short-term targets. Insufficient top management commitment, lack of a strategic quality plan, and lack of ongoing continuous education and training de-motivate employees in their quality improvement activities.

Employees' job satisfaction during the baseline, preintervention phase (2005) was $57.8 \%$ (Table 1 ). Approximately 1 in 4 employees $(26.3 \%)$ were dissatisfied with their job. Employees were least satisfied with the salaries, benefits, recognition, promotion, working conditions, organisation policies, and management. Employees were not recognised and rewarded for participating in quality management activities. They did not see the value of such work, and therefore, did not contribute to the quality management programme. Employees' payment was delayed for several months. There was a serious conflict between employees and top management. The outcome of top management policies created a stressful environment for employees. Inadequate pay, inequity at work, lack of recognition, lack of promotion prospects, lack of job security, time pressure, inadequate equipment, too much work, staff shortages, and lack of management support were the main stressors for employees. Employees' job satisfaction rose to $63.3 \%$ for the year 2007 (Table 1). Most employees expressed high levels of satisfaction, motivation, and accountability. Employees reported significant improvement in some dimensions of job satisfaction like management and supervision, organisational policies, task requirement, and working conditions. The lowest scores still fall into the same categories as the 2005 assessment (salaries and benefits). Although public managers do not have enough power as regards changing policies related to employees' salaries and promotion, work has been done to improve employees' satisfaction with the benefits and recognition schemes.
Management change and consequently a change in employee relationship management improved employees' satisfaction significantly. Participatory managerial behaviour improved employee satisfaction. The planned structural change improved employees' satisfaction. Provision of new facilities and resources encouraged employees' motivation for doing their job. Employees' roles and responsibilities were clarified. They were given the ability, motivation, and authority to improve their work quality. The SCQM programme had a great impact on personnel attitudes towards their jobs. Involvement of staff in quality management activities was correlated with a significantly higher job satisfaction. Many employees felt that their jobs had become more challenging and enjoyed the additional responsibilities. The introduction of the SCQM programme gave employees more control over their daily activities, thus, increasing job satisfaction. The SCQM programme brought the management and employees closer together. Top management paid sufficient attention to employee satisfaction, morale, development, and well-being. Employees' working stress was decreased by providing suitable resources and more facilities. Employees were encouraged to submit their ideas and opinions. The submitted ideas were evaluated by the quality management department and the selected ideas were applies. Education and training, teamwork, and management support and recognition were found to motivate employees to participate in quality management activities. This resulted in high employee motivation, high job satisfaction, and low absenteeism and turnover.

Employees' job satisfaction dropped to $62.7 \%$ for the year 2008 . Employees' job satisfaction improved during the first year of the introduction of SCQM, at an average rate of $5.5 \%(P<0.05)$. However, this accelerated rate of increase was not maintained after 2007. The introduction of procedural changes required by SCQM has caused an increase in the daily workload of the employees. In addition, employees' satisfaction with working conditions decreased. A fall in employees' satisfaction with received salaries and benefits could be related to an increase in employees' output and external factors (e.g. inflation rate in 2008 increased too much compared with 2007).

Employees' job satisfaction decreased in 2011 compared to 2008. However, they were more satisfied in comparison with the year 2005. Employees were more dissatisfied with the

Table 1. Employees' job satisfaction (on a 100 scale)

\begin{tabular}{|c|c|c|c|c|c|c|c|c|c|c|c|c|}
\hline \multirow{2}{*}{ Job satisfiers } & \multicolumn{3}{|c|}{2005} & \multicolumn{3}{|c|}{2007} & \multicolumn{3}{|c|}{2008} & \multicolumn{3}{|c|}{2011} \\
\hline & $\mathbf{P}$ & $\mathbf{E}$ & P-E & $\mathbf{P}$ & $\mathbf{E}$ & P-E & $\mathbf{P}$ & $\mathbf{E}$ & P-E & $\mathbf{P}$ & $\mathbf{E}$ & P-E \\
\hline Salaries and fringe benefits & 38.8 & 81.2 & -42.4 & 48.0 & 82.6 & -34.6 & 44.7 & 73.8 & -29.1 & 41.0 & 75.3 & -34.3 \\
\hline Recognition and promotion & 45.3 & 78.6 & -33.3 & 51.8 & 76.7 & -24.9 & 52.2 & 79.6 & -27.4 & 48.6 & 77.2 & -28.6 \\
\hline Management and Supervision & 61.2 & 79.2 & -18.0 & 66.2 & 80.0 & -13.8 & 69.3 & 77.5 & -8.2 & 64.3 & 75.7 & -11.4 \\
\hline Co-workers & 73.8 & 79.6 & -5.8 & 75.2 & 76.6 & -1.4 & 74.0 & 79.1 & -5.1 & 73.5 & 79.6 & -6.1 \\
\hline Task requirement & 65.7 & 76.3 & -10.6 & 71.3 & 76.6 & -5.3 & 71.5 & 71.1 & 0.4 & 68.0 & 73.2 & -5.2 \\
\hline Working conditions & 47.5 & 78.4 & -30.9 & 59.2 & 76.6 & -17.4 & 53.0 & 71.6 & -18.6 & 51.1 & 70.8 & -19.7 \\
\hline Nature of work & 74.0 & 75.4 & -1.4 & 73.5 & 76.0 & -2.5 & 72.0 & 81.0 & -9.0 & 73.1 & 77.4 & -4.3 \\
\hline Organisation policies & 54.7 & 78.6 & -23.9 & 64.3 & 73.3 & -9.0 & 64.5 & 70.5 & -6.0 & 58.7 & 70.0 & -11.3 \\
\hline Job security & 55.5 & 76.3 & -20.8 & 60.2 & 74.6 & -14.4 & 62.0 & 71.6 & -9.6 & 57.7 & 72.1 & -14.4 \\
\hline Overall job satisfaction & 57.8 & 78.2 & -20.4 & 63.3 & 77.0 & -13.7 & 62.7 & 75.1 & -12.4 & 59.7 & 74.6 & -14.9 \\
\hline
\end{tabular}

$\mathrm{P}=$ Perception, $\mathrm{E}=$ Expectation 
wages and fringe benefits, management, task requirements and organisational policies.

While $68 \%$ of employees agreed to leave Hospital 'A' if they could find a good job opportunity elsewhere in 2005, this figure decreased to $43 \%$ in 2008 and then increased to $45.8 \%$ in 2011 (Table 2). The difference between the two groups was statistically significant at $P<0.01$.

\section{Discussion}

The effectiveness of an organisation depends on the extent to which people perform their roles and move towards the corporate goals and objectives (28). Employees' satisfaction plays a critical role in organisational success. Employees' job satisfaction is positively related to their organisational commitment and negatively related to their turnover intention (27). Employee satisfaction can result in customer satisfaction (29). Satisfied employees are more likely to work harder and provide better services (30) and enhance organisational performance (31).

The SCQM implementation led to a higher level of employees' job satisfaction and their less intention to leave the organisation. The findings are consistent with literature suggesting that quality management implementation improves employees' outcome such as job satisfaction $(32,33)$. The SCQM application resulted in a culture change in the hospital, with improved communication, teamwork, trust, respect, and commitment to quality improvement. The implementation of SCQM model was successful in bringing managers and employees together to improve organisational performance. As a result, employee morale, and satisfaction were improved. The findings suggest that effective application of functional and cross-functional quality teams is positively related to employees' job satisfaction, which are negatively related to their turnover intention. These findings are consistent with other studies $(19,34)$.

Employees' job satisfaction improved during the first year of the introduction of SCQM. However, this accelerated rate of increase was not maintained after then mainly because of an imbalance between employees' input and output and a change in management team. The introduction of procedural changes required by SCQM has caused an increase in the daily workload of the employees. A fall in employees' satisfaction with received salaries and benefits could be related to an increase in employees' output. Similarly, Woodward and colleagues (1999) reported significant increases in depression, anxiety, emotional exhaustion, and job insecurity among hospital employees, particularly during the first year of the re-engineering change process. Job demands increased throughout the period whereas little change occurred in the employee's decision latitude (35).

The hospital top management team was changed three times during the course of SCQM implementation. The first hospital president was more task-oriented and less employee-oriented.

Table 2. Hospital recommendation for work to others by employees

\begin{tabular}{lccc}
\hline Question & $\mathbf{2 0 0 5}$ & $\mathbf{2 0 0 8}$ & $\mathbf{2 0 1 1}$ \\
\hline $\begin{array}{l}\text { Recommend the hospital for work to others } \\
\begin{array}{l}\text { Agree to leave the hospital if find a good } \\
\text { opportunity }\end{array}\end{array}$ & 27.7 & 40.5 & 39.6 \\
\hline
\end{tabular}

The second hospital president, a psychiatrist, was more employee-oriented with good managerial experience. Finally, the third hospital president was less people-oriented and taskoriented than the second CEO. Management turnover during the course of change programme influenced employees' job satisfaction significantly. A feeling of trust between employees and managers reinforces employees' tendency and commitment to adopt the change programme. Management turnover is one of the most important obstacles for successful quality management implementation (36,37). A possible explanation for this might be that management turnover increases the chance of subjective management, leading to unfavourable outcomes. Management turnover increases stress, tension, anxiety, and conflict among employees.

Top manager plays a critical role in promoting organisational change. It is important that top manager takes a leadership role, exhibits role model behaviour, shows a strong commitment to quality management, creates a supportive environment, and manages change strategically. The delivery of quality services is dependent upon motivated, qualified, satisfied, and committed employees. Employees prefer leaders who are more considerate and supportive (38). Managers should pay attention to the morale and well-being of employees.

Top managers should involve middle managers in planning and promoting the change programme. Middle managers, due to their position, can contribute greatly to quality management implementation by communicating the quality management message to employees and ensuring their commitment, converting organisational goals, objectives and strategies into detailed departmental objectives and operational activities $(39,40)$.

Employee participation in quality improvement must be recognised, supported, and acknowledged. Employees should have a positive attitude towards the quality management initiative. Lack of considering employees' benefits in the change programme at the beginning of the SCQM implementation forced them to work against the implementation of organisational change. Radical change and downsizing led to changes in the personal work situation and generated resistance. Employees were dissatisfied with the way their organisation was being run. If employees see no tangible benefit of the quality management programme, they become resistant to the programme. Incurring too much work without providing tangible benefits is the most significant reason for employee apathy. The benefits of quality management must be visible to employees in order for it to succeed and become sustainable.

For SCQM to truly have an impact, change agents should begin with the areas where such efforts result in immediate tangible results for employees to enhance their morale and motivation for continuous quality management activities. Iranian healthcare employees are motivated more by fair salaries, financial rewards, on-time payment, promotion, improved working conditions, and supportive leadership $(38,41)$. Employees will become more involved if they see the tangible benefits of the quality management programme. Appropriate recognition and reward systems are important tools to influence employees' attitudes toward improving the quality of their work. Short-term tangible results and financial incentives increase the probability of sustained success. 
Recognition and non-monetary reward systems are also critical to the long-term success of quality management initiatives.

For SCQM to have a positive impact on an organisation, managers must recognise that the theory of 'bad apples' frightens and alienates the employees. They should focus on 'what happened?' and 'why?' instead of 'who did it?' They should remove feelings of fear by assuring job security, developing a common vision, and motivating employees by utilising various monetary and non-monetary incentives to reward superior performance. Tension between management and employees increases the risk of failure of SCQM implementation.

Trust in managers is a critical factor in an employee's tendency to adopt the change programme. A feeling of trust between employees and managers reinforces employees' commitment (42). Employees prefer leaders who are more considerate and supportive. Therefore, the level of top management support for the SCQM implementation process and continuous visible leadership are vital factors in the sustainability of the change programme. Supportive managerial and clinical leadership facilitates the implementation of SCQM in healthcare organisations by providing direction and resources for continuous quality improvement. Top management visible support helps achieve the desired outcome of change acceptance.

Human resource systems, including employee selection processes, training and development, performance appraisal, and compensation and rewards must support the corporate quality culture through the development of the necessary motivation, attitudes, and the competencies. Jobs must be redesigned to give employees more flexibility, autonomy and authority, and encourage creativity. Performance appraisal and reward systems must focus more on rewarding teamwork and long-term performance.

A formal reward and recognition system that supports teamwork and links quality and higher performance with pay, encourages, and motivates employees to achieve the desired performance (43). Managers' recognition, appreciation, and acknowledgement of achieving quality objectives enhance employees' involvement in quality management activities and commitment to quality improvement (44). Recognition nurtures trust and respect between managers and employees, builds employees' self-esteem, renews their enthusiasm and reinforces desired behaviours.

\section{Limitations and implications for further research}

The focus of this study was a single general teaching hospital that has implemented SCQM. Therefore, it does limit the generalisability of the findings. Future research studies are needed to explore the impact of quality management programmes implementation on employees' outcome.

\section{Conclusion}

The SCQM programme if properly implemented and institutionalized improves employees' job satisfaction. SCQM practices such as visionary leadership, education, training, empowerment, and teamwork enhance employees' job satisfaction. Nevertheless, the implementation of the SCQM model like any other change programmes needs top management support and developing an appropriate organisational climate and culture. The SCQM programme succeeds only when the organisation is willing to change, to discard outdated management and work methods if necessary. Top management turnover is a major threat to the long-term success of the SCQM intervention and makes it very difficult to maintain the constancy of purpose expected in SCQM.

Ethical issues

Ethical codes in this study involved (i) respect for human dignity, (ii) respect for privacy and confidentiality, and (iii) respect for autonomy.

Competing interests

The author declares that he has no competing interests.

Author's contribution

AMM is the single author of the manuscript.

\section{References}

1. Boon OK, Arumugam V, Hwa TS. Does soft TQM predict employees' attitudes? The TQM Magazine 2005; 17: 279-89. doi: 10.1108/09544780510594243

2. Forza C, Filippini R. TQM impact on quality conformance and customer satisfaction: A causal model. International Journal of Production Economics 1998; 55: 1-20. doi: 10.1016/s09255273(98)00007-3

3. Agus A. TQM as a focus for improving overall service performance and customer satisfaction: An empirical study on a public service sector in Malaysia. Total Quality Management 2002; 15: 615-28. doi: 10.1080/14783360410001680107

4. Martinez-Costa M, Jimenez-Jimenez D. Are companies that implement TQM better learning organizations? An empirical study. Total Quality Management 2008; 19: 1101-15. doi: 10.1080/14783360802323446

5. Rahman S. Total quality management practices and business outcome: evidence from small and medium enterprises in Western Australia. Total Quality Management 2001; 12: 201-10. doi: 10.1080/09544120120011424

6. Agus A, Abdullah M. Total quality management practices in manufacturing companies in Malaysia: An exploratory analysis. Total Quality Management \& Business Excellence 2000; 11: 1041-51. doi: 10.1080/095441200440313

7. Hansson J, Eriksson $\mathrm{H}$. The impact of TQM on financial performance. Measuring Business Excellence 2002; 6: 44-54. doi: 10.1108/13683040210451714

8. Joiner TA. Total quality management and performance: The role of organisation support and co-worker support. International Journal of Quality \& Reliability Management 2007; 24: 617-27. doi: 10.1108/02656710710757808

9. Garvin D. Managing quality: The strategic and competitive edge. New York: Free Press; 1988.

10. Madu CN, Kuei C. Strategic Total Quality Management: Transformation process overview. Total Quality Management 1994; 5: 255-66. doi: 10.1080/09544129400000046

11. Kim KY, Chang DR. Global quality management: A research focus. Decision Sciences 1995; 26: 561-8. doi: 10.1111/j.15405915.1995.tb01440.x

12. Mosadeghrad AM. A theory of quality management. International Journal of Modelling in Operations Management 2012; 2: 89-118. doi: 10.1504/ijmom.2012.043962

13. Ennis K, Harrington D. Quality management in Irish health care. Int J Health Care Qual Assur 1999; 12: 232-43. doi: 10.1108/09526869910287305

14. Mosadeghrad AM. Obstacles to TQM success in health care 
systems. Int J Health Care Qual Assur 2013; 26: 147-73. doi: 10.1108/09526861311297352

15. Zabada CP, Rivers A, Munchus G. Obstacles to the application of total quality management in health care organisations. Total Quality Management 1998; 9: 57-66. doi: 10.1080/0954412989261

16. Mosadeghrad AM. Verification of a quality management theory: Using a Delphi study. Int J Health Policy Manag 2013; 1: 261-71. doi: 10.1080/0954412989261

17. Mosadeghrad AM. Implementing Strategic Collaborative Quality Management in Health Care Sector. International Journal of Strategic Change Management 2012; 4: 203-28.

18. Mohrman SA, Tenkasi RV, Lawler EE III, Ledford GG Jr. Total quality management: Practice and outcomes in the largest US firms. Employee Relations 1995; 17: 26-41. doi: 10.1108/01425459510086866

19. Lee LC, Yang KP, Chen TY. A quasi-experimental study on a quality circle program in a Taiwanese hospital. Int J Qual Health Care 2000; 12: 413-8. doi: 10.1093/intghc/12.5.413

20. Alsughayir $A$. Does practicing total quality management affect employee job satisfaction in Saudi Arabian organizations? European Journal of Business and Management 2014; 6: 169-75.

21. Guimaraes T. TQM's impact on employee attitudes. The TQM Magazine 1996; 8: 20. doi: 10.1108/09544789610107225

22. McAdam R, Bannister A. Business performance measurement and change management within a TQM framework', International Journal of Operations and Production Management 2001; 21: 88-107. doi: 10.1108/01443570110358477

23. Boselie P, van der Wiele T. Employee perceptions of HRM and TQM, and the effects on satisfaction and intention to leave.Managing Service Quality 2002; 12: 165-73. doi: 10.1108/09604520210429231

24. Parker SK. Longitudinal effects of lean production on employee outcomes and the mediating role of work characteristics. J Appl Psychol 2003; 88: 620-34. doi: 10.1037/0021-9010.88.4.620

25. Landsbergis PA, Cahill J, Schnall P. The impact of lean production and related new systems of work organization on worker health. J Occup Health Psychol 1999; 4: 108-30. doi: 10.1037/10768998.4.2.108

26. Vidal M. Lean production, worker employment, and job satisfaction: A qualitative analysis and critique. Critical Sociology 2007; 33: 247-78. doi: 10.1163/156916307x168656

27. Mosadeghrad AM, Ferlie E, Rosenberg D. A study of relationship between job satisfaction, organisational commitment and turnover intention among hospital employees. Health Serv Manage Res 2008; 21: 211-27. doi: 10.1258/hsmr.2007.007015

28. Oakland JS. Total quality management: Text with cases. 3 rd ed. Oxford: Butterworth- Heinemann; 2003.

29. Brown S, Lam S. A meta-analysis of relationships linking employee satisfaction to customer responses. Journal of Retailing 2008; 84: 243-55. doi: 10.1016/j.jretai.2008.06.001

30. Capelli P. A market driven approach to retaining talent. Harv Bus Rev 2000; 78: 103-11
31. Akdere M. A multi-level examination of quality-focused human resource practices and firm performance: Evidence from the US healthcare industry. International Journal of Human Resource Management 2009; 20: 1945-64. doi: 10.1080/09585190903142399

32. Sila I. Examining the effects of contextual factors on TQM and performance through the lens of organisational theories: An empirical study. Journal of Operations Management 2007; 25: 83-109. doi: 10.1016/j.jom.2006.02.003

33. Karia $\mathrm{N}$, Asaari $\mathrm{MH}$. The effects of total quality management practices on employees' work-related attitudes. The TQM Magazine 2006; 18: 30-43. doi: 10.1108/09544780610637677

34. Lagrosen Y, Backstrom I, Lagrosen S. Quality management and health: A double connection. International Journal of Quality \& Reliability Management 2007; 24: 49-61. doi: 10.1108/02656710710720321

35. Woodward CA, Shannon HS, Cunningham C, Mclntosh J, Lendrum B, Rosenbloom D, et al. The impact of re-engineering and other cost reduction strategies on the staff of a large teaching hospital: a longitudinal study. Med Care 1999; 37: 556-69. doi: 10.1097/00005650-199906000-00005

36. Mosadeghrad AM, Ferdosi M, Afshar H, Hosseini-Nejhad M. The impact of top management turnover on quality management implementation. Med Arh 2013; 67: 134-40. doi: 10.5455/ medarh.2013.67.134-140

37. Taylor WA, WrightGH. The impact of senior managers' commitment on the success of TQM programmes: An empirical study. Int $J$ Manpow 2003; 24: 535-50. doi: 10.1108/01437720310491071

38. Rad AM, Yarmohammadian MH. A study of relationship between managers' leadership style and employees' job satisfaction. Int J Health Care Qual Assur Inc Leadersh Health Serv 2006; 19: xi-xxviii. doi: 10.1108/13660750610665008

39. Baidoun S. An empirical study of critical factors of TQM in Palestinian organizations. Logistics Information Management 2003; 16: 156-71. doi: 10.1108/09576050310467296

40. Wimalasir JS, Kouzmin A. A comparative Study of employee involvement initiatives in Hong Kong and the USA. Int J Manpow 2000; 21: 614-34. doi: 10.1108/01437720010379510

41. Hamidi Y, Eivazi Z. The Relationships Among Employees' Job Stress, Job Satisfaction, and the Organizational Performance of Hamadan Urban Health Centers. Social Behavior and Personality: An international Journal 2010; 38: 963-8. doi: 10.2224/sbp.2010.38.7.963

42. Gallear D, Ghobadian A. An empirical investigation of the channels that facilitate a total quality culture. Total Quality Management 2004; 15: 1043-67. doi: 10.1080/1478336042000255497

43. Wilkinson A. Quality and the Human Factor. Total Quality Management 2004; 15: 1019-24. doi: 10.1080/1478336042000255415

44. Kassicieh SK, Yourstone SA. Training, performance evaluation, rewards, and TQM implementation success. Journal of Quality Management 1998; 3: 25-38. doi: 10.1016/s10848568(99)80102-3 


\section{Key Messages}

Implications for policy makers

- Contemporary industrial quality management practices and techniques can be adopted, adapted and successfully applied within professional healthcare organisations to achieve excellence. A well-developed and wellimplemented quality management programme offers significant benefits to organisations. Using the SCQM framework, ugmented by strategic management and project management approaches, healthcare organisations may sustain continuous quality improvement.

- Managers choosing a quality management model should remember that the model itself does not bring about improvement. Institutionalising of quality management requires commitment, effort, and resources. The SCQM model will not succeed unless a receptive context and supportive environment (supportive leadership, culture and structure) is created.

- A strong committed leadership is necessary for SCQM implementation to be successful. Without top management's stability, commitment and support, SCQM will be just another "management fad".

\section{Implications for public}

Quality has become an increasingly predominant part of our lives. People are constantly looking for quality products and services. Healthcare providers particularly doctors and nurses play crucial roles in the delivery of quality healthcare services to the public. Quality management practices such as leadership, planning, training, employee empowerment, engagement, and evaluation affect employee satisfaction and commitment, which in turn influence patient satisfaction and loyalty. 